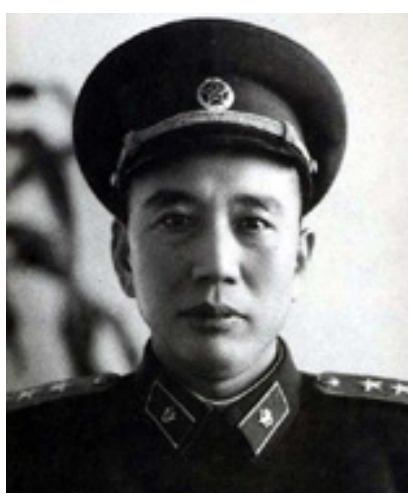

General Wang Zhen (1908-1993). Photo: Wikimedia Commons.
What is playing out in Xinjiang is a composite version of twentiethcentury authoritarian fantasies and popular dystopias that is made possible by twenty-firstcentury technology.

\section{Xinjiang Today: Wang Zhen Rides Again?}

Tom Cliff

Nostalgia for the boyishly-brutal Wang Zhen flooded across Han Xinjiang in the days, weeks, and months following the intra-communal violence of early July 2009 in Urumqi. Many Han invoked Wang Zhen's notorious approach to management of Xinjiang's non-Han (and in particular, Uyghur) population as the solution to what they termed the 'ethnic problem' (minzu wenti).

One legend-with a number of variations, as all good legends must have-venerates disproportionate response. According to this story, in 1950, as Wang Zhen's forces were spreading down into Southern Xinjiang, a Han man had unthinkingly or insensitively prepared a meal of pork in a Uyghur village, and was killed or badly beaten for the transgression. Upon hearing about this, Wang Zhen had his troops surround the village so no one could escape. He then forced the villagers to hand over the perpetrators and publicly executed them in the village square. Next he had his troops slaughter two or three pigs and boil them up in a large cauldron; at bayonet point, the troops then forced each and every remaining resident of the village to eat a bowl of boiled pork. Given the shortage of meat to feed his own soldiers, this was surely a high-cost exercise.

Two clear points can be drawn from such stories: a) Wang Zhen held the view that Uyghurs existed in Xinjiang at the sufferance of the Han-led Chinese Communist Party (CCP), and acted on that belief; b) many Han idolise Wang Zhen for, as they see it, keeping Uyghurs under control. Reflecting on what could have been done to prevent the July 2009 violence-which is widely understood across China as the indiscriminate killing of Han, including pregnant mothers, by Uyghurs of all ages and sexes for no apparent reason-some older Han in Korla reconstituted Wang Zhen's memorable (and possibly apocryphal) contribution to the ethnic policy debate. As head of the military government in Xinjiang from 1950 to 1952, Wang Zhen had apparently sized up Uyghurs as 'a troublemaking minority', and wrote to Mao Zedong advocating that they be 'thoroughly wiped out' to avoid any future problems. Even Mao felt that this was a little extremeor at least premature-so he redeployed Wang. Now, it seems that tragedy and farce have converged: Mao's successoremulator, Xi Jinping, has found his Wang Zhen. 


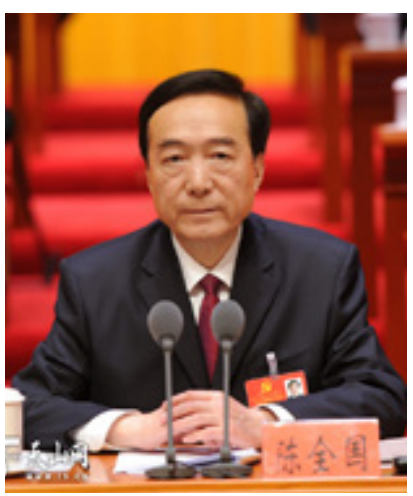

Chen Quanguo, current Communist Party Secretary of the Xinjiang Uyghur Autonomous Region. Photo: Ts.cn.

\author{
Every action and every \\ utterance goes onto \\ an unseen scorecard, \\ and saying or doing \\ 'the wrong thing' could \\ well have you taken \\ off to one of the many \\ political re-education \\ centres that Chen \\ Quanguo dramatically \\ expanded as soon as he \\ took over the reins in \\ Urumqi.
}

As Party Secretary of Xinjiang, Chen Quanguo has apparently taken up Wang Zhen's unfinished business. But while Wang Zhen just wanted Uyghurs to get out of the way of his developmental plans or be wiped away completely, the current system is both destructive and inclusive. What is playing out in Xinjiang is a composite version of twentiethcentury authoritarian fantasies and popular dystopias that is made possible by twenty-first-century technology (Clarke 2018; Vanderklippe 2017).

The system starts with total surveillance (Millward 2018). When Uyghurs have any communication with people outside China (including their own relatives), they get visits from the Public Security Bureau within an hour or two, and suffer repetitive questioning about who the caller was, what they are doing overseas, and what they spoke about. The police, of course, know exactly what they spoke about because they were listening. The point is to let the Uyghurs know that they are being watched and listened to very closely. Every action and every utterance goes onto an unseen scorecard, and saying or doing 'the wrong thing' could well have you taken off to one of the many political re-education centres that Chen Quanguo dramatically expanded as soon as he took over the reins in Urumqi (Radio Free Asia 2017a). Simply having spent time overseas whilst not in the company of an authorised tour group puts you under suspicion; students studying in Islamic countries such as Egypt or Turkey have been told to return to China, then met at the airport and immediately whisked away for re-education.

The next step is to subject select Uyghurs-and now also Kazakhs and other non-Han people-to a totalising regime of physical and psychological abuse. Horrific, and credible, reports of what goes on inside the political re-education camps have been coming through since the beginning of 2017: inmates made to repeatedly recite lines of gratitude to the Party while being tortured with white noise, contortion, and marching exercises; sleep deprivation to break their spirit (ChinaAid 2018). The high rate of deaths in custody supports reports of vicious beatings and intrusive physical torture (Radio Free Asia 2018b, 2017b). An estimated 5 to 10 percent of the Uyghur population of Xinjiang-up to 800,000 people-is now locked up in these camps, with more being taken in all the time (Human Rights Watch 2017; Radio Free Asia 2018a).

Overseas, in a dormitory near you, Uyghur students wake screaming in a cold sweat; they are having nightmares about their family members back in Xinjiang, or their own future without a home or a family. Their families have told them not to return under any circumstances, and now refuse to take their calls. Sub-prefectural police departments in Xinjiang 
The upkeep cost of this surveillance state can only be estimated, but it is undoubtedly very high. The political cost is immeasurable: over the past two decades, repressive practices aimed at Uyghurs in Xinjiang have negatively impacted inter-ethnic relations, provoked a series of violent incidents, and caused Xinjiang residents to feel insecure, irrespective of their ethnicity. send text messages to Uyghurs from their area who have been living overseas for years, demanding passport and residency information. The logic is consistent with social control practices within China: 'You are originally of our locale, you belong to us.' But these police are not primarily aiming to gather information, they are sending a warning: 'We know your telephone number, we know your name, we know where your family members live in Xinjiang. Be careful, don't be critical.' In such ways, family members residing in Xinjiang are used as leverage in attempts to control the activities of Uyghurs living overseas (Denyer 2018; U.S. Embassy 2018). All this, too, amounts to a very high-cost exercise-and on a much larger scale than Wang Zhen's pork.

The cost is both financial and political. The upkeep cost of this surveillance state can only be estimated, but it is undoubtedly very high (Zenz 2018). The political cost is immeasurable: over the past two decades, repressive practices aimed at Uyghurs in Xinjiang have negatively impacted interethnic relations, provoked a series of violent incidents, and caused Xinjiang residents to feel insecure, irrespective of their ethnicity. Han, Hui, Kazakh, and Uyghur people alike fear for personal or family members' safety and economic prospects; many even fear the environment in which they live, and the place to which they all feel that they belong. And although the Chinese state media claimed in March 2017 that the number of violent terrorist incidents had dropped with 'religious extremism notably curbed' by April 2018, my sense is that these feelings of insecurity have increased dramatically over the very same period (Cao and Cui 2017; Xinhua 2018). This is clearly no basis upon which to build a harmonious, moderately prosperous society, as is the stated aim of the Party-state in Xinjiang and across the country (An 2017).

So, why is the Party-state doing this? I raised this question in a recent discussion with a senior colleague. We should assume, I said, that we do not know the ultimate aim of the Chinese leadership in Xinjiang-and thus we do not know what motivates their policies and practices. 'That's a bit conspiratorial, isn't it?' my colleague replied. 'They say that they want to prevent violent terrorist attacks, promote economic development, and assure long-term social and political stability. Why wouldn't they want that?'

'Why not?' I now return to the question. I do not have the answer, of course, because I do not have access to any of the internal communications-far less to informal and unspoken communications-that might give me clues as to what that answer might be. But I do have a proposed starting point. I think it is important to reject once and for all the idea that Chinese leaders do not realise the effects of what they 


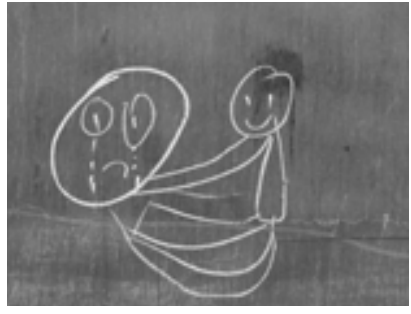

Graffiti on the external wall of an apartment building inhabited by Uyghur families within an oil company compound. Photo: Tom Cliff are doing. Chinese leaders do not need policy advice from foreign critics. They have access to much more and better information; they have legions of people to gather and process this information. The leaders themselves are neither stupid nor inexperienced in matters of social management. They, too, can surely see that the hyper-securitisation of Xinjiang is producing widespread feelings of insecurity and consuming vast amounts of human, material, and political resources, and thereby laying the groundwork for social and political instability for decades into the future (Rife 2018). And thus my questions 'Why are they doing it? What do they hope to achieve?' become relevant. 